\title{
Cerebellar Depolarization-Induced Suppression of Inhibition Is Mediated by Endogenous Cannabinoids
}

\author{
Anatol C. Kreitzer and Wade G. Regehr \\ Department of Neurobiology, Harvard Medical School, Boston, Massachusetts 02115
}

Depolarization of cerebellar Purkinje neurons transiently suppresses IPSCs through a process known as depolarizationinduced suppression of inhibition (DSI). This IPSC suppression occurs presynaptically and results from an unknown retrograde signal released from Purkinje cells. We recorded IPSCs from voltage-clamped Purkinje cells in cerebellar brain slices to identify the retrograde signal for cerebellar DSI. We find that DSI persists in the presence of the broad-spectrum metabotropic glutamate receptor antagonist LY341495 and the GABA $\mathrm{B}_{\mathrm{B}}$ receptor antagonist CGP55845, suggesting that the retrograde signal is not acting through these receptors. However, an antagonist of the cannabinoid CB1 receptor AM251 completely blocked cerebellar DSI. Additionally, the cannabinoid receptor

Depolarization-induced suppression of inhibition (DSI), which is a form of fast retrograde signaling from postsynaptic neurons back to inhibitory cells that innervate them (Llano et al., 1991a; Pitler and Alger, 1992, 1994; Vincent and Marty, 1993; Alger and Pitler, 1995), has been described in both the cerebellum and the hippocampus. In the cerebellum, depolarization of Purkinje cells results in a suppression of spontaneous IPSCs (sIPSCs), which arise primarily from basket cells and stellate cells in the molecular layer. This suppression lasts for tens of seconds and is thought to occur presynaptically, because the amplitude of miniature IPSCs (mIPSCs) during DSI remains unchanged (Llano et al., 1991a). Cerebellar DSI is blocked by chelating calcium in Purkinje cells (Llano et al., 1991a; Glitsch et al., 2000), implicating postsynaptic calcium in the release of an unidentified retrograde signal.

In the cerebellum, the identity of the retrograde signal remains unknown, whereas in the hippocampus, the retrograde messenger for DSI has been identified recently as an endogenous cannabinoid (Ohno-Shosaku et al., 2001; Wilson and Nicoll, 2001). Cannabinoids are a likely candidate in the cerebellum as well, because endogenous cannabinoids are known to be released from Purkinje cells during depolarization, where they can transiently inhibit excitatory synaptic inputs (Kreitzer and Regehr, 2001). Additionally, CB1 receptors are located on interneurons in cerebellar cortex (Matsuda et al., 1993; Tsou et al., 1998; Egertova and Elphick, 2000), and synthetic cannabinoid agonists suppress sIPSCs (Takahashi and Linden, 2000).

\footnotetext{
Received June 18, 2001; revised July 20, 2001; accepted July 26, 2001.

This work was supported by National Institutes of Health Grant R01-NS32405-01. We thank Dawn Blitz, Adam Carter, Kelly Foster, and Matthew Xu-Friedman for comments on this manuscript.

Correspondence should be addressed to Wade G. Regehr, Department of Neurobiology, Harvard Medical School, 220 Longwood Avenue, Boston, MA 02115. E-mail: wade_regehr@hms.harvard.edu.

Copyright (C) 2001 Society for Neuroscience $\quad 0270-6474 / 01 / 210001-05 \$ 15.00 / 0$
}

agonist WIN55,212-2 suppressed IPSCs and occluded any additional IPSC reduction by DSI. These results indicate that cannabinoids released from Purkinje cells after depolarization activate CB1 receptors on inhibitory neurons and suppress IPSCs for tens of seconds. Cerebellar DSI thus shares a common retrograde messenger with DSI in the hippocampus and depolarization-induced suppression of excitation in the cerebellum, suggesting that retrograde synaptic suppression by endogenous cannabinoids represents a widespread signaling mechanism.

Key words: cannabinoid; DSI; cerebellum; Purkinje cell; stellate cell; basket cell

However, other evidence suggests a potential role for GABA or glutamate as the retrograde signal in cerebellar DSI. In the cortex, dendritic release of GABA from inhibitory neurons results in a retrograde inhibition of synaptic inputs through activation of $\mathrm{GABA}_{\mathrm{B}}$ receptors on presynaptic neurons (Zilberter et al., 1999); similar mechanisms could exist at synapses onto Purkinje cells, which are also GABAergic. In the hippocampus, such a mechanism is less likely because the CA1 pyramidal neurons that elicit DSI are glutamatergic. Additionally, it has been proposed that cerebellar DSI is mediated by glutamate release from Purkinje cells, which could act at presynaptic group II metabotropic glutamate receptors (mGluRs) on interneurons to suppress IPSCs (Glitsch et al., 1996). Therefore, the identity of the retrograde messenger for cerebellar DSI remains an open question.

Here we report that the magnitude of cerebellar DSI is unaffected by antagonists of mGluRs or $\mathrm{GABA}_{\mathrm{B}}$ receptors. However, we find that activation of cannabinoid $\mathrm{CB} 1$ receptors is required for suppression, because antagonists of the CB1 receptor completely eliminate cerebellar DSI, and agonists of the CB1 receptor occlude DSI. Cerebellar DSI therefore shares a common retrograde signal with both hippocampal DSI and cerebellar depolarization-induced suppression of excitation (DSE) and im-

This article is published in The Journal of Neuroscience, Rapid Communications Section, which publishes brief, peerreviewed papers online, not in print. Rapid Communications are posted online approximately one month earlier than they would appear if printed. They are listed in the Table of Contents of the next open issue of JNeurosci. Cite this article as: JNeurosci, 2001, 21:RC174 (1-5). The publication date is the date of posting online at www.jneurosci.org.

http://www.jneurosci.org/cgi/content/full/5720 
plicates endogenous cannabinoids as widespread retrograde signaling molecules.

\section{MATERIALS AND METHODS}

Sagittal slices $(250 \mu \mathrm{M}$ thick) were cut from the cerebellar vermis of 14to 21-d-old Sprague Dawley rats. Slices were superfused with an external saline solution containing (in mM): $125 \mathrm{NaCl}, 2.5 \mathrm{KCl}, 2 \mathrm{CaCl}_{2}, 1 \mathrm{MgCl}_{2}$, $26 \mathrm{NaHCO}_{3}, 1.25 \mathrm{NaH}_{2} \mathrm{PO}_{4}$, and 25 glucose (bubbled with $95 \% \mathrm{O}_{2}-5 \%$ $\mathrm{CO}_{2}$ ). 1,2,3,4-Tetrahydro-6-nitro-2,3-dioxo-benzo[f]quinoxaline-7sulfonamide $(10 \mu \mathrm{M})$ was added to the external solution to suppress synaptic currents mediated by AMPA receptors. $(\alpha S)-\alpha$-amino- $\alpha-(1 S, 2 S)-2-$ carboxycyclopropyl-9H-xanthine-9-propanoic acid (LY341495), (2S)-3[(1S)-1-(3,4-dichlorophenyl)ethyl]amino-2-hydroxypropyl)(phenylmethyl) phosphinic acid (CGP55845), and $N$-(piperidin-l-yl)-5-(4-iodophenyl)-1(2,4-dichlorophenyl)-4-methyl-1H-pyrazole-3-carboxamide (AM251) were purchased from Tocris Cookson (Ballwin, MO). $R(+)$-[2,3-dihydro-5methyl-3-[(morpholinyl)methyl]pyrrolo[1,2,3-de]-1,4-benzoxazinyl]-(1naphthalenyl) methanone (WIN55,212-2) was purchased from Sigma (St. Louis, MO).

Whole-cell recordings of Purkinje cells were obtained as described previously (Llano et al., 1991c). Glass electrodes (2-4 M $\Omega$ ) were filled with an internal solution containing (in $\mathrm{mM}$ ): $150 \mathrm{CsCl}, 1$ EGTA, 10 HEPES, $0.1 \mathrm{CaCl}_{2}, 4.6 \mathrm{MgCl}_{2}, 2 \mathrm{Mg}$-ATP, and $0.3 \mathrm{Na}-\mathrm{GTP}$, adjusted to pH 7.3 with CsOH. Internal solutions also contained $5 \mathrm{~mm} \mathrm{QX-314}$ ( $N$-(2,6-dimethylphenylcarbamoylmethyl)-triethylammonium bromide) to block voltage-dependent sodium channels. Inhibitory synaptic currents were monitored at a holding potential of $-60 \mathrm{mV}$. The $80 \mathrm{sec}$ trials used to assay DSI were separated by $60 \mathrm{sec}$. Access resistance and leak currents were monitored, and experiments were rejected if these parameters changed significantly during recording.

DSI was quantified by calculating synaptic charge (Pitler and Alger, 1994). Slow shifts in baseline attributable to calcium-activated currents after depolarization were first subtracted from the recordings by determining the maximum data value for each $100 \mathrm{msec}$ window throughout a trace. An interpolated function fit through these points was then subtracted from the trace. This procedure did not change the amplitude or time course of synaptic currents. After the subtraction, integration of the currents yielded total synaptic charge. However, synaptic charge was not analyzed during the depolarization or in the $3 \mathrm{sec}$ after depolarization because of shunting from large calcium-activated chloride conductances (Llano et al., 1991a). Analysis was performed using custom routines written in Igor Pro (WaveMetrics Inc., Lake Oswego, OR).

EPSCs were filtered at $1 \mathrm{kHz}$ with a four-pole Bessel filter. All signals were digitized at $2 \mathrm{kHz}$ with a 16 bit analog-to-digital converter (InstruTech, Great Neck, NY), with Pulse Control software (Herrington and Bookman, 1995).

\section{RESULTS}

We recorded from voltage-clamped Purkinje cells in sagittal cerebellar brain slices and monitored sIPSCs. Cerebellar DSI is characterized by a reduction in the amplitude and frequency of IPSCs (Llano et al., 1991a), and we therefore measured synaptic charge, which is sensitive to changes in these parameters (Pitler and Alger, 1994).

\section{Effects of mGluR and $\mathrm{GABA}_{B}$ antagonists on cerebellar DSI}

To test the hypothesis that mGluRs and $\mathrm{GABA}_{\mathrm{B}}$ receptors are involved in DSI, we recorded sIPSCs from Purkinje cells using 80 sec trials (Fig. 1A). During each trial, baseline synaptic charge was determined during the first $20 \mathrm{sec}$ of recording. The Purkinje cell was then depolarized for $1 \mathrm{sec}$ (Fig. $1 A$, arrow), and the recording continued for $60 \mathrm{sec}$. DSI is clearly visible in these trials as a decrease in the amplitude of sIPSCs after depolarization (Fig. 1A). To quantify DSI, we measured synaptic charge for each $2 \mathrm{sec}$ epoch during the trials. Figure $1 C$ shows the average synaptic charge for five trials in control conditions. After application of the high-affinity broad-spectrum mGluR receptor antagonist LY341495 (100 $\mu \mathrm{M})$ (Fitzjohn et al., 1998) and the high-affinity $\mathrm{GABA}_{\mathrm{B}}$ receptor antagonist CGP55845 (2 $\left.\mu \mathrm{M}\right)(\mathrm{Da}-$
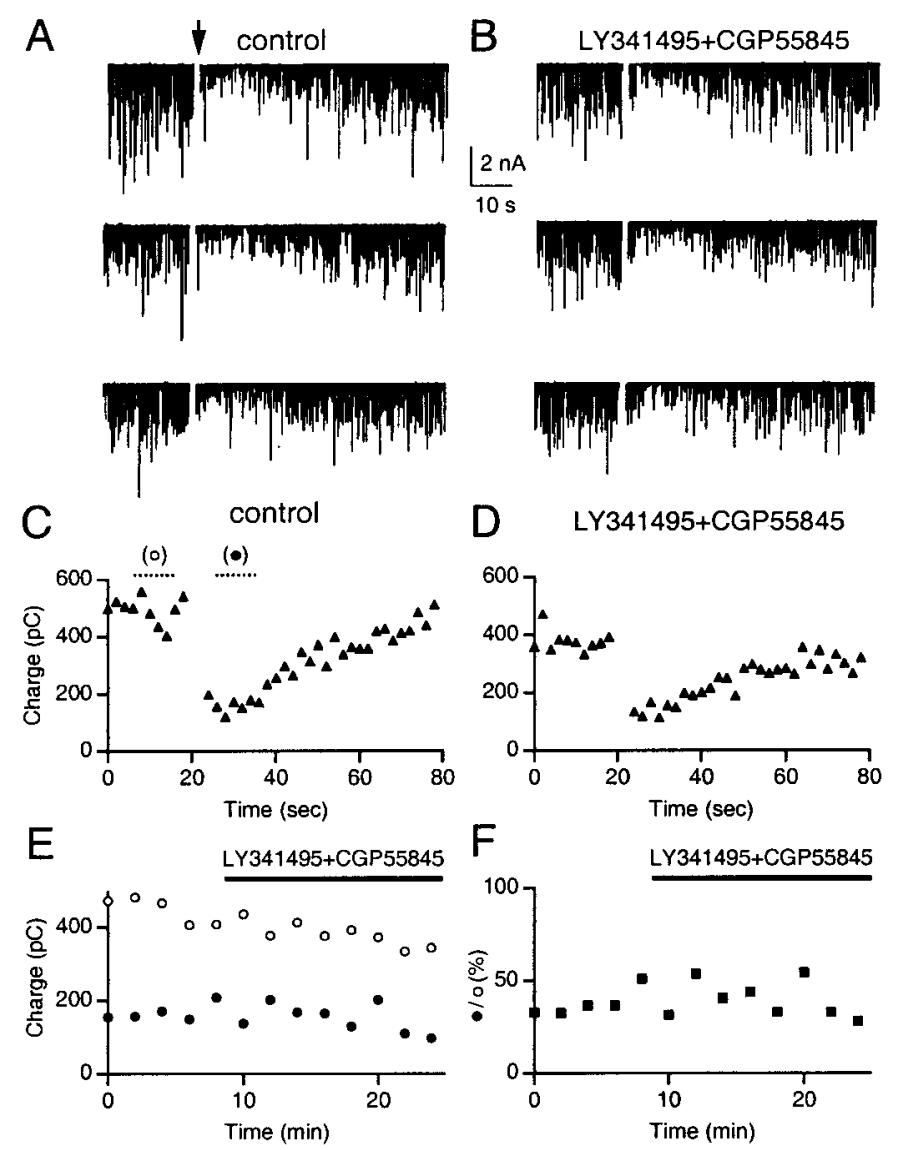

Figure 1. Cerebellar DSI is not mediated by activation of mGluRs or $\mathrm{GABA}_{\mathrm{B}}$ receptors. Representative traces of spontaneous IPSCs recorded from a Purkinje cell in control conditions $(A)$ and after application of LY341495 $(100 \mu \mathrm{M})$ and CGP55845 $(2 \mu \mathrm{M})(B)$. During each trial, the Purkinje cell was depolarized from -60 to $0 \mathrm{mV}$ for $1 \mathrm{sec}$ at the time marked by the arrow in $A(t=20 \mathrm{sec})$. Slow shifts in the baseline attributable to calcium-activated currents after depolarization have been subtracted for clarity (see Material and Methods). The average synaptic charge ( filled triangles) was calculated in $2 \mathrm{sec}$ epochs for five control trials $(C)$ and for five trials in the presence of metabotropic antagonists $(D)$. Baseline charge, calculated from 6-16 sec (marked by dashed line in $C$; open circles) and charge after depolarization, calculated from 26-36 sec (marked by dashed line in $C$; filled circles, E), and the amount of DSI ( filled squares, $F$ ), calculated as charge $\mathrm{DsI}_{\mathrm{DS}} /$ charge $_{\text {baseline, }}$, are plotted for each trial. Drugs were applied during the time marked by the bar in $E$ and $F$.

vies et al., 1993), the magnitude of DSI is unchanged (Fig. 1B,D). In Figure $1 E$, baseline synaptic charge (open circles; calculated from times shown in Fig. $1 C$ ) and synaptic charge during DSI ( filled circles; calculated from times shown in Fig. 1C) are plotted for each trial in the experiment. The amount of DSI, calculated as charge $_{\mathrm{DSI}} /$ charge $_{\text {baseline }}$, remains unchanged for the duration of the experiment, even after application of $m$ GluR and $\mathrm{GABA}_{\mathrm{B}}$ antagonists (Fig. $1 F$ ). This shows the stability of DSI during the course of an experiment and also demonstrates that activation of mGluRs and $\mathrm{GABA}_{\mathrm{B}}$ receptors is not required for cerebellar DSI. Summary data are shown in Figure 4.

\section{Effects of cannabinoids on cerebellar DSI}

To test whether endogenous cannabinoids play a role in cerebellar DSI, we used the same protocol outlined for Figure 1. We recorded sIPSCs from Purkinje cells and elicited DSI at the time marked by the arrow in Figure $2 A$. In Figure $2 C$, the average 
A

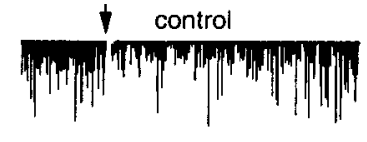

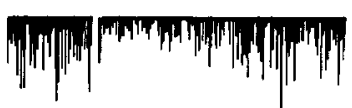

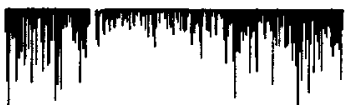

C

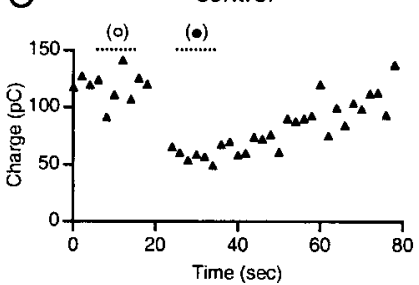

$E$

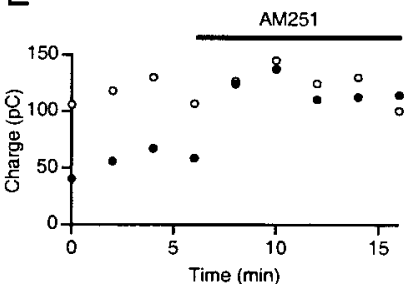

\section{B}
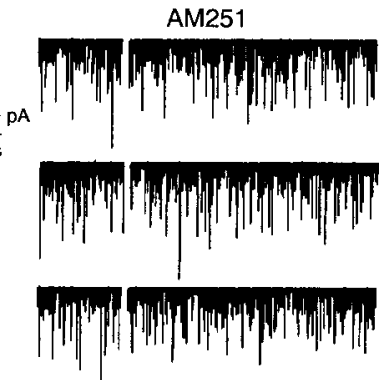

D

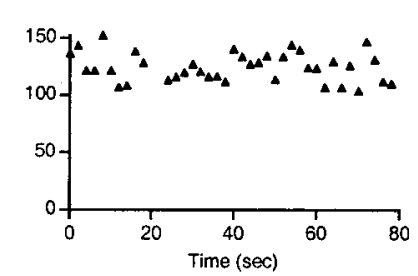

$\mathrm{F}$

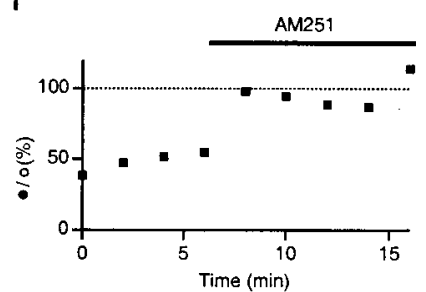

Figure 2. A cannabinoid receptor antagonist eliminates cerebellar DSI. Representative traces of spontaneous IPSCs recorded from a Purkinje cell in control conditions $(A)$ and after application of AM251 $(1 \mu \mathrm{M})(B)$. The average synaptic charge (filled triangles) was calculated for five control trials $(C)$ and for five trials in the presence of the CB1 antagonist $(D)$. Baseline charge (open circles) and charge after depolarization ( filled circles, $E$ ) and DSI ( filled squares, $F$ ) are plotted for each trial. AM251 was applied during the time marked by the bar in $E$ and $F$.

synaptic charge was calculated for four trials in control conditions. After application of the high-affinity CB1 receptor antagonist AM251 (1 $\mu \mathrm{M})$ (Gatley et al., 1996), DSI is completely eliminated in all subsequent trials (Fig. $2 F$ ) (see Fig. $4 C$ ). In Figure 2E, baseline synaptic charge (open circles; calculated from times shown in Fig. $2 C$ ) and synaptic charge during DSI (filled circles; calculated from times shown in Fig. $2 C$ ) are plotted for each trial in the experiment.

DSI in the cerebellum, but not the hippocampus, is characterized by a reduction in mIPSC frequency (Alger and Pitler, 1995). Therefore, we performed additional experiments $(n=5$ cells $)$ in the presence of TTX $(1 \mu \mathrm{M})$ to test whether the inhibition of mIPSCs during DSI is also mediated by endogenous cannabinoids. Application of TTX reduced synaptic charge by $\sim 80 \%$. After Purkinje cell depolarization, mIPSC frequency is reduced to $69 \pm 3 \%$ of baseline, and synaptic charge is reduced to $75 \pm$ $3 \%$ of baseline. After bath application of AM251, Purkinje cell depolarization did not elicit any reduction in MIPSC frequency $(102 \pm 1 \%$ of baseline) or synaptic charge $(104 \pm 3 \%$ of baseline).

Similar experiments were conducted using WIN55,212-2, an agonist of the CB1 receptor (Figure 3). We first recorded sIPSCs in control conditions and elicited DSI at the time marked by the arrow in Figure $3 A$. The average synaptic charge for five trials in control conditions is shown in Figure 3C. After application of the cannabinoid receptor agonist WIN55,212-2 (5 $\mu \mathrm{M})$, IPSCs were

\section{A}
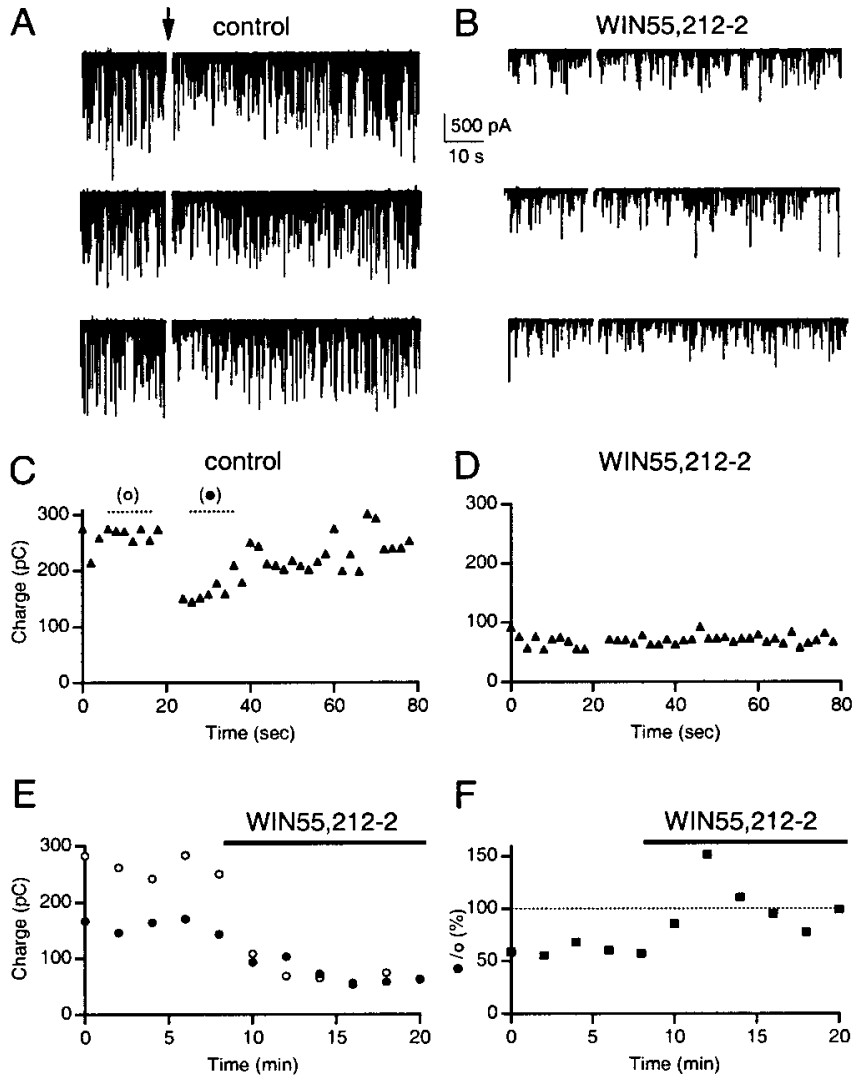

Figure 3. A cannabinoid receptor agonist occludes cerebellar DSI. Representative traces of spontaneous IPSCs recorded from a Purkinje cell in control conditions $(A)$ and after application of WIN55,212-2 $(5 \mu \mathrm{M})(B)$. The average synaptic charge (filled triangles) was calculated for five control trials $(C)$ and for five trials in the presence of the CB1 agonist $(D)$. Baseline charge (open circles) and charge after depolarization ( filled circles, E) and DSI (filled squares, $F$ ) are plotted for each trial. WIN55,212-2 was applied during the time marked by the bar in $E$ and $F$.

reduced and Purkinje cell depolarization did not elicit any additional suppression (Fig. $3 B, D$ ). In Figure $3 E$, baseline synaptic charge (open circles; calculated from times shown in Fig. $3 C$ ) and synaptic charge during DSI ( filled circles; calculated from times shown in Fig. $3 C$ ) are plotted for each trial in the experiment. After application of WIN55,212-2, DSI is completely eliminated (Figs. $3 F, 4 D$ ).

\section{DSI is mediated by endogenous cannabinoids}

A summary of the pharmacological manipulations used to identify the retrograde messenger for cerebellar DSI is shown in Figure 4. The amplitude and time course of cerebellar DSI, as measured by normalized synaptic charge (percentage of baseline), is shown in control conditions ( $n=18$ cells) (Fig. $4 A$ ), in the presence of the mGluR and $\mathrm{GABA}_{\mathrm{B}}$ antagonists LY341495 $(100 \mu \mathrm{M})$ and CGP55845 ( $2 \mu \mathrm{M} ; n=4$ cells) (Fig. $4 B)$, in the presence of AM251 ( $1 \mu \mathrm{M} ; n=5$ cells) (Fig. $4 C)$, and in the presence of WIN55,212-2 ( $5 \mu \mathrm{M} ; n=4$ cells) (Fig. $4 D$ ). After depolarization, synaptic charge, relative to baseline, was $44 \pm 3 \%$ (Fig. 4A) in control conditions, $47 \pm 5 \%$ in the presence of LY341495 and CGP55845 (Fig. 4B), $95 \pm 5 \%$ in the presence of AM251 (Fig. 4C), and $93 \pm 6 \%$ in the presence of WIN55,212-2 (Fig. 4D). WIN55,212-2 also decreased baseline synaptic charge to $44 \%$ of control. 

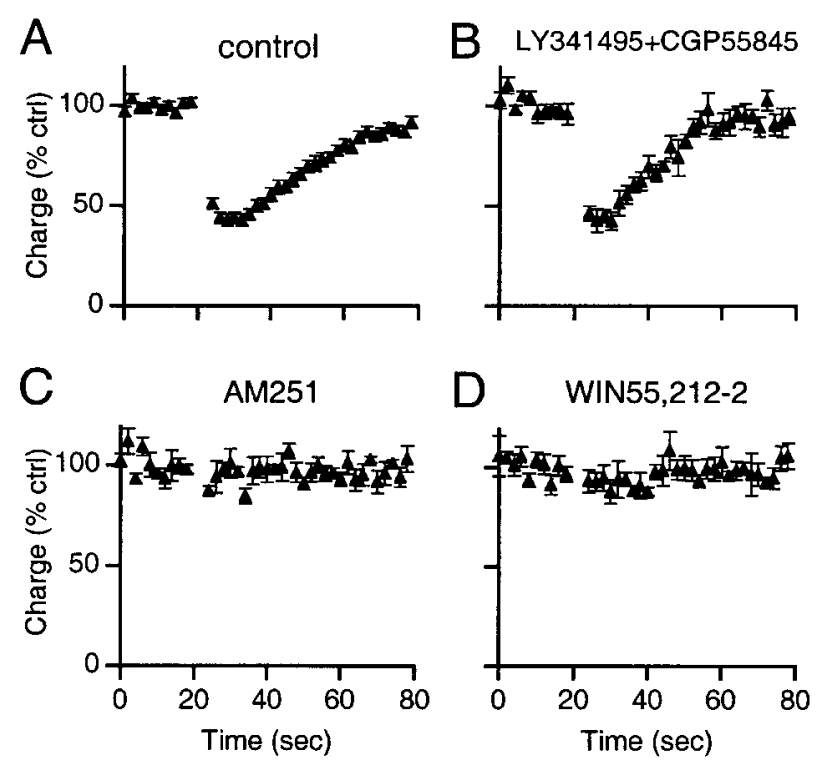

Figure 4. Summary of pharmacological manipulations on cerebellar DSI. Normalized charge ( filled triangles) was calculated in $2 \mathrm{sec}$ epochs for trials in control conditions $(n=18$ cells) $(A)$, in the presence of LY341495 $(100 \mu \mathrm{M})$ and CGP55845 $(2 \mu \mathrm{M} ; n=4$ cells $)(B)$, in the presence of AM251 ( $1 \mu \mathrm{M} ; n=5$ cells) $(C)$, and in the presence of WIN55,212-2 (5 $\mu \mathrm{M} ; n=4$ cells) $(D)$. Error bars represent SEM.

\section{DISCUSSION}

We demonstrate that cerebellar DSI is mediated by endogenous cannabinoids that are released by Purkinje cells during depolarization and act presynaptically to inhibit IPSCs for tens of seconds. This result, together with the finding that endogenous cannabinoids inhibit excitatory synapses (Kreitzer and Regehr, 2001), shows that Purkinje cells can modulate both their excitatory and inhibitory inputs on rapid timescales through a common retrograde signal. Cerebellar DSI also shares a common retrograde signal with hippocampal DSI (Ohno-Shosaku et al., 2001; Wilson and Nicoll, 2001), suggesting that retrograde signaling by endogenous cannabinoids may be widespread in the CNS.

\section{Differences between cerebellar and hippocampal DSI}

The finding that cerebellar DSI is mediated by endogenous cannabinoids clarifies a mechanistic difference between cerebellar and hippocampal DSI. In the cerebellum, the frequency of mIPSCs is reduced during DSI (Llano et al., 1991a), whereas in the hippocampus, the frequency of mIPSCs is unchanged (Pitler and Alger, 1994). Changes in the frequency of miniature events are associated with direct actions on release machinery, downstream of calcium influx (Dittman and Regehr, 1996), and this raised the possibility that additional signaling pathways were involved in cerebellar DSI. However, we show that mIPSC suppression during cerebellar DSI is also mediated by endogenous cannabinoids. This result is consistent with a previous study in the cerebellum in which application of the cannabinoid receptor agonist WIN55,212-2 was found to decrease the frequency of mIPSCs (Takahashi and Linden, 2000). In the hippocampus, where DSI does not reduce mIPSC frequency, WIN55,212-2 also has no effect on mIPSC frequency (Hajos et al., 2000). Thus, mechanistic differences between DSI in the cerebellum and the hippocampus arise downstream of $\mathrm{CB} 1$ receptor activation.

\section{Comparison of DSE and DSI in the cerebellum}

Because both excitatory and inhibitory synapses are modulated by release of endogenous cannabinoids from Purkinje cells, differential effects on excitation or inhibition could have important implications for Purkinje cell activity after depolarization. After a $1 \mathrm{sec}$ depolarization of a Purkinje cell, parallel fiber EPSCs are inhibited by $\sim 85 \%$ and climbing fiber EPSCs are inhibited by $\sim 60 \%$ (Kreitzer and Regehr, 2001), whereas synaptic charge from IPSCs is reduced by $\sim 60 \%$. This suggests that, in general, parallel fiber synapses are more sensitive to cannabinoids than either climbing fiber or inhibitory synapses. However, efficacy of cannabinoid signaling in the cerebellum is likely to be influenced by a number of factors, including the mGluR-coupled release of calcium from internal stores by $\mathrm{IP}_{3}$ (Llano et al., 1991b; Khodakhah and Ogden, 1993; Finch and Augustine, 1998; Takechi et al., 1998), calcium-induced calcium release (Llano et al., 1994), the localization and spatial extent of the cannabinoid signal, and the patterns of activity in presynaptic neurons (Dittman et al., 2000; Kreitzer and Regehr, 2000).

\section{REFERENCES}

Alger BE, Pitler TA (1995) Retrograde signaling at GABAA-receptor synapses in the mammalian CNS. Trends Neurosci 18:333-340.

Davies CH, Pozza MF, Collingridge GL (1993) CGP 55845A: a potent antagonist of $\mathrm{GABA}_{\mathrm{B}}$ receptors in the CA1 region of rat hippocampus. Neuropharmacology 32:1071-1073.

Dittman JS, Regehr WG (1996) Contributions of calcium-dependent and calcium-independent mechanisms to presynaptic inhibition at a cerebellar synapse. J Neurosci 16:1623-1633.

Dittman JS, Kreitzer AC, Regehr WG (2000) Interplay between facilitation, depression, and residual calcium at three presynaptic terminals. J Neurosci 20:1374-1385.

Egertova M, Elphick MR (2000) Localisation of cannabinoid receptors in the rat brain using antibodies to the intracellular $\mathrm{C}$-terminal tail of CB. J Comp Neurol 422:159-171.

Finch EA, Augustine GJ (1998) Local calcium signalling by inositol1,4,5-trisphosphate in Purkinje cell dendrites. Nature 396:753-756.

Fitzjohn SM, Bortolotto ZA, Palmer MJ, Doherty AJ, Ornstein PL, Schoepp DD, Kingston AE, Lodge D, Collingridge GL (1998) The potent mGlu receptor antagonist LY341495 identifies roles for both cloned and novel mGlu receptors in hippocampal synaptic plasticity. Neuropharmacology 37:1445-1458.

Gatley SJ, Gifford AN, Volkow ND, Lan R, Makriyannis A (1996) 123I-labeled AM251: a radioiodinated ligand which binds in vivo to mouse brain cannabinoid CB1 receptors. Eur J Pharmacol 307:331-338.

Glitsch M, Llano I, Marty A (1996) Glutamate as a candidate retrograde messenger at interneurone-Purkinje cell synapses of rat cerebellum. J Physiol (Lond) 497:531-537.

Glitsch M, Parra P, Llano I (2000) The retrograde inhibition of IPSCs in rat cerebellar Purkinje cells is highly sensitive to intracellular $\mathrm{Ca}^{2+}$. Eur J Neurosci 12:987-993.

Hajos N, Katona I, Naiem SS, MacKie K, Ledent C, Mody I, Freund TF (2000) Cannabinoids inhibit hippocampal GABAergic transmission and network oscillations. Eur J Neurosci 12:3239-3249.

Herrington J, Bookman RJ (1995) Pulse control V4.5: IGOR XOPs for patch clamp data acquisition. Miami: University of Miami.

Khodakhah K, Ogden D (1993) Functional heterogeneity of calcium release by inositol triphosphate in single Purkinje neurones, cultured cerebellar astrocytes, and peripheral tissues. Proc Natl Acad Sci USA 90:4976-4980.

Kreitzer AC, Regehr WG (2000) Modulation of transmission during trains at a cerebellar synapse. J Neurosci 20:1348-1357.

Kreitzer AC, Regehr WG (2001) Retrograde inhibition of presynaptic calcium influx by endogenous cannabinoids at excitatory synapses onto Purkinje cells. Neuron 29:717-727.

Llano I, Leresche N, Marty A (1991a) Calcium entry increases the sensitivity of cerebellar Purkinje cells to applied GABA and decreases inhibitory synaptic currents. Neuron 6:565-574.

Llano I, Dreessen J, Kano M, Konnerth A (1991b) Intradentic release of calcium induced by glutamate in cerebellar Purkinje cells. Neuron 7:577-583.

Llano I, Marty A, Armstrong CM, Konnerth A (1991c) Synaptic- and agonist-induced excitatory currents of Purkinje cells in rat cerebellar slices. J Physiol (Lond) 434:183-213.

Llano I, DiPolo R, Marty A (1994) Calcium-induced calcium release in cerebellar Purkinje cells. Neuron 12:663-673. 
Matsuda LA, Bonner TI, Lolait SJ (1993) Localization of cannabinoid receptor mRNA in rat brain. J Comp Neurol 327:535-550.

Ohno-Shosaku T, Maejima T, Kano M (2001) Endogenous cannabinoids mediate retrograde signals from depolarized postsynaptic neurons to presynaptic terminals. Neuron 29:729-738.

Pitler TA, Alger BE (1992) Postsynaptic spike firing reduces synaptic GABAA responses in hippocampal pyramidal cells. J Neurosci 12:4122-4132.

Pitler TA, Alger BE (1994) Depolarization-induced suppression of GABAergic inhibition in rat hippocampal pyramidal cells: $G$ protein involvement in a presynaptic mechanism. Neuron 13:1447-1455.

Takahashi KA, Linden DJ (2000) Cannabinoid receptor modulation of synapses received by cerebellar Purkinje cells. J Neurophysiol 83:1167-1180.
Takechi H, Eilers J, Konnerth A (1998) A new class of synaptic response involving calcium release in dendritic spines. Nature 396:757-760.

Tsou K, Brown S, Sanudo-Pena MC, Mackie K, Walker JM (1998) Immunohistochemical distribution of cannabinoid CB1 receptors in the rat central nervous system. Neuroscience 83:393-411.

Vincent P, Marty A (1993) Neighboring cerebellar Purkinje cells communicate via retrograde inhibition of common presynaptic interneurons. Neuron 11:885-893.

Wilson RI, Nicoll RA (2001) Endogenous cannabinoids mediate retrograde signalling at hippocampal synapses. Nature 410:588-592.

Zilberter Y, Kaiser KM, Sakmann B (1999) Dendritic GABA release depresses excitatory transmission between layer $2 / 3$ pyramidal and bitufted neurons in rat neocortex. Neuron 24:979-988. 